\title{
The Dental, Oral, Medical Epidemiological (DOME) Study: Protocol and Study Methods
}

\author{
Galit Almoznino ${ }^{1,2,3}$ Ron Kedem ${ }^{4}$ Ronit Turgeman ${ }^{5}$ Tarif Bader $^{6}$ Nirit Yavnai ${ }^{7}$ Dorit Zur ${ }^{4}$ \\ Boaz Shay ${ }^{3}$
}

${ }^{1}$ Big Biomedical Data Research Laboratory, Hebrew University, Hadassah School of Dental Medicine, Jerusalem, Israel

2 Department of Oral Medicine, Sedation and Maxillofacial Imaging, Hebrew University, Hadassah School of Dental Medicine, Jerusalem, Israel

${ }^{3}$ Department of Endodontics, Hebrew University, Hadassah School of Dental Medicine, Jerusalem, Israel

${ }^{4}$ Medical Information Department, Medical Corps, Israel Defense Forces, Tel-Hashomer, Israel

${ }^{5}$ Chief Dental Surgeon Headquarters, Medical Corps, Israel Defense Forces, Tel-Hashomer, Israel

${ }^{6}$ Surgeon General's Headquarters, Israel Defense Forces, Ramat Gan and Department of Military Medicine, Hebrew University, Jerusalem, Israel

${ }^{7}$ Medical Research and Academy Section, Medical Corps, Israel Defense Forces, Israel

Methods Inf Med 2020;59:119-130.

\begin{abstract}
Address for correspondence Galit Almoznino, DMD, MSc, MHA, MPH, Department of Oral Medicine, Sedation and Maxillofacial Imaging, Hebrew University, Hadassah School of Dental Medicine, Israeli Society of Oral Medicine (ISOM), P.O. Box 12000, Jerusalem 91120 , Israel (e-mail: galit@almoznino.com).
\end{abstract}

\section{Abstract}

Keywords

- epidemiological studies

- dental health

- informatics

- oral health

- electronic medical records
Objectives To develop and present the methods utilized for the Dental, Oral, Medical Epidemiological (DOME) study.

Methods The DOME is an electronic record-based cross-sectional study, that was conducted to measure the dental, periodontal, and oral morbidities and their associations with systemic morbidities, among a nationally representative sample of young to middle-aged adults military personnel from the IDF (Israel Defense Forces). To that end, we developed a strict protocol including standardized terminology, data collection, and handling.

Results Data for the DOME study was derived simultaneously from three electronic records of the IDF: (1) a central demographic database, (2) the dental patient record (DPR), and (3) the medical computerized patient record (CPR). The established DOME repository includes socio-demographic, dental and medical records of 132,354 young to middle-age military personnel from the IDF, who attended the dental clinics during the year 2015. Records of general military personnel $(N>50,000)$, with no recorded dental visits during the study period, served as a control group regarding all other parameters except dental. The DOME study continues and is currently collecting longitudinal data from the year 2010 until 2020. The IDF employs a standardized uniform administrative and clinical work-up and treatment protocols as well as uniform computerized codes. We describe the standardized definitions for all the parameters that were included: socio-demographics, health-related habits, medical and dental attendance patterns, and general and dental health status. Multicollinearity analysis results of the sociodemographic and medical study parameters are presented.

Conclusion Standardized work-up and definitions are essential to establish the centralized DOME data repository to study the extent of dental and systemic morbidities and their associations. received

January 21, 2020

accepted after revision

August 28, 2020

published online

October 20, 2020 (c) 2020. Thieme. All rights reserved. Georg Thieme Verlag KG,

Rüdigerstraße 14,

70469 Stuttgart, Germany
DOI https://doi.org/

$10.1055 / \mathrm{s}-0040-1718582$.

ISSN 0026-1270. 


\section{Introduction}

Quantifying dental and oral morbidities in a meaningful and reproducible manner has been an ongoing challenge for oral epidemiologists and clinicians. ${ }^{1-3}$ To develop policy and allocate resources for medical and dental care in an informed manner, health authorities need to be familiar with the data on the extent of dental and systemic morbidity. In Israel, there is no formal authority responsible for collecting dental and oral morbidity data, although the ministry of health has suggested that an epidemiologic survey should be performed every 5 years. ${ }^{4}$ Consequently, there is a lack of information regarding the status of dental, periodontal, and oral morbidity among the Israeli population, and regarding its trends throughout the years. ${ }^{4}$

To address this gap in the literature, the current project, termed as "Dental, Oral, Medical Epidemiological (DOME)" study, aims to study the dental, periodontal and oral morbidities and analyze their associations with systemic morbidities, among a unique nationally representative sample of young to middle-aged adults, i.e., the military personnel in the Israel Defense Forces (IDF). The military population in Israel is large, and serves as a reliable source of data for epidemiologic studies among young and middle-aged adults, partially because conscription exists in Israel for all Jewish, Druze, or Circassian citizens over the age of $18 .^{5}$ Israeli Arabs, Druze women, and ultraorthodox religious Jewish citizens are exempt from military service ${ }^{6,7}$ and therefore not included in this study.

Several authors documented associations between health status and socioeconomic variables. ${ }^{8,9}$ Associations between dental and periodontal morbidities and various systemic diseases had been also documented. In particular, periodontitis had been linked to various systemic diseases such as metabolic syndrome ${ }^{10-13}$ and each of its components and consequences, including type 2 diabetes, ${ }^{14}$ hypertension, ${ }^{15,16}$ hyperlipidemia, ${ }^{17}$ abdominal obesity, ${ }^{18}$ cardiovascular disease, ${ }^{19}$ and stroke. ${ }^{20}$ The underlying mechanisms for these associations remain unclear, although inflammatory mechanisms seem to play an important role. ${ }^{18,21-26}$ Moreover, there are well-known common risk factors, ${ }^{27}$ such as increased age, smoking, and lifestyle, for many chronic diseases, including metabolic syndrome, hypertension, hyperlipidemia, diabetes type 2, and cardiovascular disease. ${ }^{28-30}$ These risk factors had been also linked to oral health status, including periodontitis. $27,31,32$

Based on an extensive literature review, the secondary goals of the DOME project were to evaluate the extent of dental and systemic morbidities and their complex associations. Specifically, the secondary aims were to analyze the associations and correlations between dental, periodontal, and oral morbidities and: socio-demographics, health-related habits, medical and dental attendance patterns, and general health status. It should be noted that medically complex patients serve in the IDF, in noncombat occupations, and even subjects deemed unfit for service for physical or mental health reasons can apply for volunteer positions. ${ }^{33}$ Volunteers have the same access and rights to dental care as soldiers in mandatory service. Criteria for volunteering in the IDF for military exemption recipients are publicly available. $^{34}$

This paper aims to present and discuss in detail the development, and study methods of the DOME project, including the standardized terminology, data collection, handling, and analysis. In our series of papers that are due to follow, we will present the data on each specific dependent variable that we analyzed.

\section{Methods}

The DOME project is a records-based study, which consists of the socio-demographic, dental and medical and records of young to middle-age military personnel, serving in mandatory and career service, who attended routine dental screenings and treatments at any of the military dental clinics of the IDF, between January 1st, 2015 and January 1st, 2016. Sociodemographic and medical parameters of these patients were compared with a control group data from the central IDF database, with records from over 50,000 general military personnel, with no recorded visits to military dental clinics during the study period. The control data were obtained on the mid-study period (June 30th, 2015). The DOME study continues and is currently collecting longitudinal data from the year 2010 until 2020. Data mining was performed by the Medical Information Department, General Surgeon Headquarter, Medical Corps, Tel-Hashomer, Israel. The database is completely anonymous.

All patients received free and unconditional treatment as IDF military personnel do not incur any medical and/or dental expenses. ${ }^{35,36}$ Commanders are obligated to allow their subordinates full access to all medical and/or dental services, independent of rank and position. ${ }^{35}$ Moreover, a baseline evaluation of dental status is performed during the mandatory dental examination which takes place during the first 4 months of recruitment. ${ }^{5}$

\section{Ethical Considerations}

The study adhered to the STROBE guidelines and was approved by the Medical Corps, IDF, Institutional Review Board, approval number: IDF-1281-2013. Since this retrospective study only involved anonymous medical records analysis, the IRB gave an exemption from written informed consent.

\section{Results}

\section{Informatics standards in the IDF Medical Corps}

The data warehouse (DWH) of the IDF Medical Corps (Version $11 \mathrm{~g}$ of the Oracle Database) combines information from several operational source systems into one comprehensive database (-Fig. 1). Data from the operational sources are extracted and then replicated to the DWH via ETL (ExtractTransform-Load) processes nightly. The ETL tool used is Informatica version 9.6.1. The collected data are classified in the DWH into Oracle database schema according to the data world of the original operational sources (e.g., computerized patient record [CPR] schema, dental patient record 


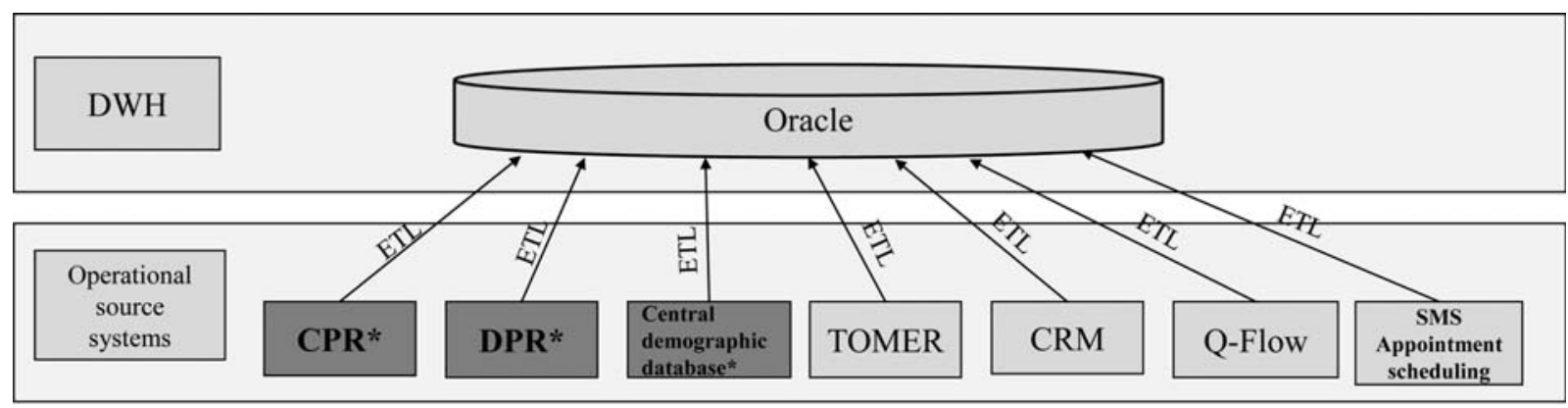

\begin{abstract}
*Operational source systems used in the DOME study: CPR: computerized patient record system DPR: Dental Patient Record

TOMER: a table of treatment codes standardized across military clinics and services. CRM- Customer relationship management system.

Q-Flow: a telephone appointment scheduling platform.
\end{abstract}

Fig. 1 The architecture of the data warehouse (DWH) of the IDF Medical Corps.

[DPR]schema, etc.). All pieces of information have two patient identifiers (civilian and military ID numbers), allowing all data from a specific individual to be combined into a single record.

Data collection: The records were extracted from the databases using the military ID number and validated using the civilian ID number. Data management from the DWH was performed using SAS version 7.1. To develop the DOME repository, data were drawn simultaneously from three electronic records:

1. Dental patient record: This electronic dental record system stores the data of all dental care in the IDF. ${ }^{5}$ The DPR includes the patient's dental, periodontal, and oral records as well as treatment plan and actual treatments, imaging results, and consultation requests. The DPR is stored on a structured query language server 2005.

2. Computerized patient record: is a comprehensive electronic medical record system found in all military primary care and specialty clinics. ${ }^{37}$ It contains electronically maintained information about the patient's general health status and care. Data include clinical documentation, medical issues, medications prescribed, physicians' notes (e.g., medical history and follow-up), laboratory and imaging results, and consultation request. ${ }^{37}$ The CPR is stored in version $11 \mathrm{~g}$ of the Oracle database.

3. IDF's central demographic database: keeps the records of the personal socio-demographic profiles of the military population. ${ }^{38}$ The central demographic database is stored in version $11 \mathrm{~g}$ of the Oracle database.

Preparation and cleaning of data for analysis: Following the integration of the extracted data from the IDF Medical Corps' DWH, the data was prepared, cleaned, harmonized, anonymized, and transformed into an Excel file suitable for analyses. The objective of this stage was to diminish noise by detecting and removing outliers (e.g., due to typographical errors) and by evaluating data quality. An outlier is a biologically irrelevant measurement (e.g., a height value of $4 \mathrm{~m}$ ), or an impossible number of dental visits (e.g., hundreds per year). Outliers are detected using nonparametric statistical analyses, due to lack of knowledge regarding the data distribution.

\section{Inclusion Criteria}

1. Military personnel in mandatory and career service.

2. The existence of subject data in the demographic database, CPR, and DPR. For controls: the existence of subject data in the CPR, and socio-demographic records.

\section{Exclusion Criteria}

1. Excluded from military service.

2. Lack of socio-demographic, dental, or medical data in the demographic database, and/or CPR and DPR.

Data were taken simultaneously from the three sources according to the inclusion and exclusion criteria. This established the centralized data repository of the DOME study that includes socio-demographic, medical, and dental data of 132,354 records of subjects who attended the dental clinics and as well as records of controls $(N>50,000)$, with no recorded dental visits during the study period.

\section{Study Variables}

Definitions of Dental, Periodontal, Oral, and Maxillofacial Variables

Standardization Methods of the Dental Department of the IDF Medical Corps

Examinations and treatment plans were made according to the guidelines of the Dental Department of the IDF medical corps. ${ }^{5}$ According to these guidelines, the dental examinations were performed in military dental clinics, in an indoor setting, with optimal light, dental mirror, and UNC-15 (University of North Carolina, North Carolina, United States) periodontal probe, Hu-Friedy Manufacturing Co., Chicago, Illinois, United States. 
The guidelines require a pair of vertical bilateral bitewings for the molar and premolar areas for all examinees and periapical radiographs for deep caries, endodontically treated teeth, and periodontal disease. ${ }^{5}$ As part of the routine training, all military dentists complete a dental officers' course at the Military Medicine Academy, as the last chapter in their training as officers. During this course, the guidelines and protocols of the Dental Department of the IDF medical corps are reviewed. This ensures the standardization of evaluation, treatment, and administrative methods among all IDF military dentists. Quality assessment (QA) of treatment plans and adherence to these guidelines are checked regularly by the regional military chief dental surgeons. ${ }^{5}$ This allows the medical-dental system to be homogenous, with standardized uniform administrative as well as clinical workup and treatment process. ${ }^{35}$

\section{Standardized Codes for Dental Procedures in the Dental Patient Record (DPR)}

Standardized uniform codes are employed in the DPR for all dental procedures. - Table 1 presents the nomenclature of the standardized DPR codes for dental procedures and their equivalent nomenclature by the American Dental Association (ADA) Current Dental Terminology (CDT). ${ }^{39}$

Each dental code appears twice in the database per subject. The first time, in the treatment plan (as treatment needed) and then after the treatment was performed. Although orthodontic treatments are performed in the IDF, orthodontic treatment assessment was beyond the scope of this study.

\section{Mandatory Standardized Form to Record Health-Related Habits and Diagnoses in the DPR}

The opening screen of the DPR includes a mandatory form filled by military dentists according to the guidelines of the Dental Department of the IDF medical corps which includes the following:

(a) Presence of periodontitis: - Table 1 presents the nomenclature of the standardized DPR codes for periodontal examinations and procedures and their equivalent nomenclature by the ADA-CDT. The current periodontitis definitions were published in the special issue: Proceedings of the World Workshop on the Classification of Periodontal and Peri-Implant Diseases and Conditions. ${ }^{40}$ This workshop was planned and conducted jointly by the American Academy of Periodontology (AAP) and the European Federation of Periodontology in November 2017. The special issue was published in June $2018,{ }^{40}$ and it incorporates papers $^{40-63}$ that summarize the current /modern definitions used in the assessment of periodontal and periimplant diseases and conditions. In the present study, periodontitis is defined according to the guidelines of the AAP during 2010 to $2018,{ }^{64}$ and thereafter (20182020) the definitions were according to the new guidelines presented above. Furthermore, even before 2018, routinely collected data (see below) included age, smoking habits, metabolic morbidity including diabetes, and for those with diabetes the glycated hemoglobin (HbA1c) was also measured. Moreover, due to possible pseudo pockets, ${ }^{65}$ radiographic bone loss was considered mandatory to establish a diagnosis of periodontitis according to the guidelines of the Dental Department of the IDF. Bitewing radiographs are routinely inspected by dentists for the loss of periodontal support. Radiographic bone loss is defined as a distance between the crestal margin and the cementoenamel junction, which is greater than $2 \mathrm{~mm}$, in more than one tooth, with no visible cause, ${ }^{66}$ such as faulty restoration, overhang, etc.

(b) The number of missing teeth: Is the count of missing teeth for any reason, including extractions due to decay, periodontal, or orthodontic reasons. Wisdom teeth were not included in the count.

(c) The presence of oral soft tissue disease or suspected pathological lesions in the soft tissues of the oral cavity and lips during a dental examination is recorded routinely as are all suspected pathological X-ray findings in bitewings and/or periapical and/or panoramic X-rays during a dental examination.

(d) Assessment of oral health-related habits: These include three questions aimed to assess the oral health-related habits of the patients:

1. Teeth brushing: Do you brush your teeth at least once a day? yes/no.

2. Cariogenic diet consumption: Do you consume snacks and/or sweets between meals or instead of meals? yes/ no.

3. Sweetened beverages consumption: Do you consume at least one cup per day of sweetened (artificial and/or sugar-based) beverages? yes/no.

Assessment of the current smoking status and alcohol consumption (yes/no) was found in the CPR as recorded by the general physician.

\section{Definitions of the Sociodemographic Variables}

The following socio-demographic variables drawn from the IDF's central demographic database were included:

1. Age: in years; Sex : men/women.

2. Service type and duration: measured in months. ${ }^{7}$

3. Type of army unit: combat or support. ${ }^{7}$

4. Education: (a) high school graduate with 12 years of school education, (b) technical college graduate, and (c) academic education.

5. Intellectual capability and quality group: All draftees are thoroughly screened for physical and mental pathology 1 year before mandatory military service, to determine their eligibility for service and their potential for various military roles. ${ }^{6,67}$ Screening includes the intellectual capability score (ICS) and quality group score (QGS):

(a) Intellectual capability score: Intelligence is based on an evaluation of verbal, nonverbal, and mathematical cognitive abilities, taken at this first draft. ${ }^{5,6,67}$ The sum of the test results forms a validated measure of 
Table 1 Nomenclature of the standardized Dental Patient Record (DPR) codes for dental procedures and their equivalent nomenclature in the American Dental Association (ADA) Current Dental Terminology (CDT)-2018 ${ }^{44}$

\begin{tabular}{|c|c|c|}
\hline $\begin{array}{l}\text { DPR code-abbreviations of the } \\
\text { procedure in Hebrew }\end{array}$ & Nomenclature & $\begin{array}{l}\text { Equivalent ADA } \\
\text { CDT-2018 code }\end{array}$ \\
\hline $\begin{array}{l}\text { Emergency dental/medical } \\
\text { referrals }\end{array}$ & $\begin{array}{l}\text { Urgent referral of a patient to a specialist evaluation because of a } \\
\text { pathological finding suspicious to be a significant medical condition } \\
\text { (e.g. suspected cancer, systemic illness) }\end{array}$ & None \\
\hline Dental examination & Comprehensive oral evaluation for a new or established patient & D0150 \\
\hline Oral medicine examination & Comprehensive oral evaluation-new or established patient & $\begin{array}{l}\text { D0150 } \\
\text { D0160 }\end{array}$ \\
\hline Periodontal examination & $\begin{array}{l}\text { Comprehensive periodontal evaluation-new or established patient } \\
\text {-done by a periodontist }\end{array}$ & D0180 \\
\hline $\begin{array}{l}\text { Periodontal scaling and root } \\
\text { planning }\end{array}$ & $\begin{array}{l}\text { Periodontal scaling and root planning-four or more teeth per } \\
\text { quadrant }\end{array}$ & D4341 \\
\hline Periodontal maintenance & Periodontal maintenance & D4910 \\
\hline $\begin{array}{l}\text { Temporomandibular disorders } \\
\text { examination }\end{array}$ & $\begin{array}{l}\text { Comprehensive evaluation of temporomandibular disorders-new } \\
\text { or established patient }\end{array}$ & None \\
\hline Oral hygiene instructions & Oral hygiene instructions & D1330 \\
\hline $\begin{array}{l}\text { Caries arresting medicament } \\
\text { application }\end{array}$ & Interim caries arresting medicament application-per tooth & D1354 \\
\hline Scaling & $\begin{array}{l}\text { Scaling in presence of generalized moderate or severe gingival } \\
\text { inflammation-full mouth, after oral evaluation }\end{array}$ & D4346 \\
\hline $\begin{array}{l}\text { Scaling done by a dental } \\
\text { hygienist }\end{array}$ & $\begin{array}{l}\text { Scaling in presence of generalized moderate or severe gingival } \\
\text { inflammation-full mouth, after oral evaluation done by a dental } \\
\text { hygienist }\end{array}$ & D4346 \\
\hline Scaling and root planning & Periodontal scaling and root planning & $\begin{array}{l}\text { D4341 } \\
\text { D4342 }\end{array}$ \\
\hline Amalgam surface-1 & Amalgam-one surface, permanent & D2140 \\
\hline Amalgam surface-2 & Amalgam-two surfaces, permanent & D2150 \\
\hline Amalgam surface-3 & Amalgam-three and more surfaces, permanent & D2160 \\
\hline Amalgam crown & Amalgam-four or more surfaces, permanent & D2161 \\
\hline Resin-based composite & Resin-based composite-one to four surfaces, anterior & $\begin{array}{l}\text { D2330, D2331 } \\
\text { D2332, D2335 }\end{array}$ \\
\hline Composite crown & Resin-based composite crown, anterior & D2390 \\
\hline Root canal treatment-1 (RCT-1) & Endodontic therapy, one root canal (excluding final restoration) ${ }^{\mathrm{a}}$ & D3310 \\
\hline Root canal treatment-2 (RCT-2) & Endodontic therapy, two root canals (excluding final restoration) ${ }^{\mathrm{a}}$ & D3320 \\
\hline Root canal treatment-3 (RCT-3) & Endodontic therapy, three root canals (excluding final restoration) ${ }^{a}$ & D3330 \\
\hline Root canal treatment-4 (RCT-4) & Endodontic therapy, four root canals (excluding final restoration) ${ }^{a}$ & D3330 \\
\hline Root canal treatment-5 (RCT-5) & Endodontic therapy, five root canals (excluding final restoration) ${ }^{a}$ & D3330 \\
\hline \multicolumn{3}{|c|}{ Total number of teeth with endodontic treatment $=$ RCT- $1+$ RCT-2 + RCT-3 + RCT-4 + RCT-5 } \\
\hline $\begin{array}{l}\text { Atypical root canal treatment-1 } \\
\text { (ARCT-1) }\end{array}$ & $\begin{array}{l}\text { Endodontic therapy, atypical root canal anatomy, one root canal } \\
\text { (excluding final restoration) }^{\mathrm{a}}\end{array}$ & D3310 \\
\hline $\begin{array}{l}\text { Atypical root canal treatment-2 } \\
\text { (ARCT-2) }\end{array}$ & $\begin{array}{l}\text { Endodontic therapy, atypical root canal anatomy, two root canals } \\
\text { (excluding final restoration) }^{\mathrm{a}}\end{array}$ & D3320 \\
\hline $\begin{array}{l}\text { Atypical root canal treatment-3 } \\
\text { (ARCT-3) }\end{array}$ & $\begin{array}{l}\text { Endodontic therapy, atypical root canal anatomy, three root canals } \\
\text { (excluding final restoration) })^{\mathrm{a}}\end{array}$ & D3330 \\
\hline $\begin{array}{l}\text { Atypical root canal treatment-4 } \\
\text { (ARCT-4) }\end{array}$ & $\begin{array}{l}\text { Endodontic therapy, atypical root canal anatomy, four root canals } \\
\text { (excluding final restoration) }^{\mathrm{a}}\end{array}$ & D3330 \\
\hline \multicolumn{3}{|c|}{ Total number of teeth with atypical root canal anatomy with endodontic therapy $=$ ARCT- $1+$ ARCT- $2+$ ARCT-3 + ARCT- 4} \\
\hline Retreatment root canal-1 (RRC-1) & $\begin{array}{l}\text { Retreatment of previous root canal therapy, one root canal (ex- } \\
\text { cluding final restoration) }^{\mathrm{a}}\end{array}$ & D3346 \\
\hline
\end{tabular}


Table 1 (Continued)

\begin{tabular}{|c|c|c|}
\hline $\begin{array}{l}\text { DPR code-abbreviations of the } \\
\text { procedure in Hebrew }\end{array}$ & Nomenclature & $\begin{array}{l}\text { Equivalent ADA } \\
\text { CDT-2018 code }\end{array}$ \\
\hline Root canal retreatment-2 (RRC-2) & $\begin{array}{l}\text { Retreatment of previous root canal therapy, two root canals (ex- } \\
\text { cluding final restoration) }\end{array}$ & D3347 \\
\hline Root canal retreatment-3 (RRC-3) & $\begin{array}{l}\text { Retreatment of previous root canal therapy, three root canals } \\
\text { (excluding final restoration) }^{\mathrm{a}}\end{array}$ & D3348 \\
\hline Root canal retreatment-4 (RRC-4) & $\begin{array}{l}\text { Retreatment of previous root canal therapy, four root canals (ex- } \\
\text { cluding final restoration) }^{\mathrm{a}}\end{array}$ & D3348 \\
\hline Root canal retreatment-5 (RRC-5) & $\begin{array}{l}\text { Retreatment of previous root canal therapy, five root canals (ex- } \\
\text { cluding final restoration) }\end{array}$ & D3348 \\
\hline \multicolumn{3}{|c|}{ Total number of teeth with retreatment of previous root canal therapy $=$ RRC- $1+R R C-2+R R C-3+R R C-4+R R C-5$} \\
\hline Extraction & $\begin{array}{l}\text { Extraction erupted tooth or exposed root (elevation and/or forceps } \\
\text { removal) }\end{array}$ & D7140 \\
\hline Surgical extraction & $\begin{array}{l}\text { - Extraction erupted tooth requiring removal of bone and/or } \\
\text { sectioning of a tooth and including elevation of the mucoperiosteal } \\
\text { flap if indicated. } \\
\text { - Removal of an impacted tooth (soft tissue/partially } \\
\text { bony/completely bony). }\end{array}$ & $\begin{array}{l}\text { D7210, D7220 } \\
\text { D7230, D7240 }\end{array}$ \\
\hline Implant placement & Surgical placement of implant body: endosteal implant & D6010 \\
\hline Second stage implant surgery & Second stage implant surgery & D6011 \\
\hline Implant removal & Implant removal, by a report & D6100 \\
\hline Crown & $\begin{array}{l}\text { Crown-porcelain/ceramic } \\
\text { Crown-porcelain fused to high noble metal } \\
\text { Crown-porcelain fused to a predominantly base metal } \\
\text { crown-full cast predominantly base metal } \\
\text { Crown-full cast noble metal }\end{array}$ & $\begin{array}{l}\text { D2740 } \\
\text { D2750 } \\
\text { D2751 } \\
\text { D2791 } \\
\text { D2790 } \\
\text { D2792 }\end{array}$ \\
\hline Implant-supported crown & $\begin{array}{l}\text { Implant-supported porcelain/ceramic crown } \\
\text { Implant-supported porcelain fused to metal crown (titanium, tita- } \\
\text { nium alloy, high noble metal) } \\
\text { Implant-supported a metal crown (titanium, titanium alloy, high } \\
\text { noble metal) }\end{array}$ & $\begin{array}{l}\text { D6065 } \\
\text { D6066 } \\
\text { D6067 }\end{array}$ \\
\hline Interim abutment & Interim abutment & D6051 \\
\hline Direct post and core & Prefabricated post and core in addition to a crown & D2954 \\
\hline Indirect post and core & Post and core in addition to the crown, indirectly fabricated & D2952 \\
\hline Occlusal guard & Occlusal guard & D9940 \\
\hline Missed appointment & Missed appointment & D9986 \\
\hline
\end{tabular}

${ }^{a}$ Equivalent endodontic CDT codes, address endodontic treatment according to the tooth (anterior, premolar, and molars), while the DPR classifies according to the number of root canals.

general intelligence (IQ) scored on a 9-point scale that is adjusted from time to time. ${ }^{68,69}$ The ICS score ranges from 10 to 90 , with 90 being roughly equivalent to an IQ of 135 and above. ${ }^{67}$

(b) Quality group score: This score integrates several personality characteristics designed to assess combat suitability and future military performance. ${ }^{69}$ It is comprised of educational background, test scores, and a personal interview, which are combined with an actuarial procedure into a single 16-point scale score between 41 and 56..$^{67,69}$

6. Socio-economic status (SES): SES was based on the locality of residence taken from Israeli Ministry of the interior records, which stratifies all local councils and municipalities data into 10 socio-economic docile groups determined by the Israeli Central Bureau of Statistics. ${ }^{70}$ The SES considers age distribution, available workforce, level of unemployment, level of education (proportion of undergraduate students and those entitled to a high school diploma), average per capita income, and proportion of income support recipients. SES was classified into three categories: low ( $1 \mathrm{st}-4$ th deciles), medium (5th-7th), and high (8th-10th), as reported previously. ${ }^{71-73}$

7. Countries of origin and countries of birth: The country of origin for Israeli-born individuals was defined by paternal or paternal grandfather's country of birth if the father was 
born in Israel, as described previously. ${ }^{38,74,75}$ Countries of origin and countries of birth were categorized into the following geographic areas: Western Europe, Former Soviet Union (FSU), Asia, Ethiopia, Africa, North America, South America, and Israel.

8. The locality of residence: was determined according to both stratification of urban versus rural as well as Jewish versus non-Jewish population in the area. The locality was classified into three categories: urban Jewish, urban nonJewish, and rural.

9. Living in central versus peripheral rings of a city/town: the central ring is the economic, employment, and social center of a city/town compared with its peripheral areas.

\section{Definitions of General Health Status Parameters}

\section{Mandatory Standardized Form for Recording General Health Status Diagnoses in the Computerized Patient Record}

Medical care is provided according to the guidelines of the IDF Medical Corps. ${ }^{69}$ During the education and training military physicians are taught the appropriate military medical terminology and guidelines. ${ }^{69} \mathrm{QA}$ of health care was performed regularly by QA teams, as was previously detailed. ${ }^{76}$

General health status parameters are drawn from the CPR include:

1. Medical profile: During the draft process, all recruits undergo a through a medical and psychiatric evaluation, to determine eligibility for service. ${ }^{67}$ Subsequently, each examinee is given a specific standardized numerical code, termed the medical profile. The medical profile is a scoring system the IDF uses to determine medical suitability. Although the scale is ordinal, it is nonsequential, ${ }^{67}$ and includes the following values (from highest to lowest): 97 (most physically capable), 82, 77, 72, 65, 64, 45, $35,30 / 25,24,21$ (unfit for service for medical health reasons). Explanation regarding each score can be found in IDF websites (http://draftidf.co.il/profile/). The medical profile is updated during military service according to the soldier's physical or mental state, either by the authorities or by the soldier. ${ }^{67,77}$ In the present study, the medical profile was categorized as follows: high: 73 to 97 , intermediate: 65 to 72, and low profile: 21 to 64 .

2. Medical diagnoses: include the current medical diagnoses of the patient in the CPR, documented by a primary care provider and/or specialists.

(a) Complex variable definitions: The Medical Corps developed complex variable definitions for three medical conditions: hypertension, hyperlipidemia, and diabetes (-Table 2). These definitions are generated and stored in the computerized database and are used to periodically assess these morbidities by IDF authorities.

(b) Other diagnoses recorded in the CPR and collected for the current study include obstructive sleep apnea, fatty liver, anemia, osteoporosis, status post (S/P) transient ischemic attack, and S/P stroke.

(c) Family history of the following: diabetes, heart problems, stroke, sudden death, and alcoholism.

(d) Auxiliary examinations: including blood pressure and body mass index (BMI). ${ }^{68,78}$

1. Systolic and diastolic blood pressure - Blood pressure is routinely measured by a medic before any medical examination, after 5-10 minutes of rest in the sitting position, with an appropriately sized cuff on the right arm, at heart level using a manual sphygmomanometer, as detailed elsewhere. $^{78}$

Table 2 Complex variable definitions for hypertension, diabetes, and hyperlipidemia

\begin{tabular}{|c|c|}
\hline Diagnosis & Criteria for diagnosis establishment \\
\hline Hypertension & $\begin{array}{l}\text { 1. Valid military disability code for hypertension. } \\
\text { 2. Results of the blood pressure test at any stage prior to the examination period that meet the following } \\
\text { criteria: } \\
\text { a. One measurement higher or equal to } 110 \mathrm{~mm} \mathrm{Hg} \text { diastolic or } 180 \mathrm{~mm} \mathrm{Hg} \text { systolic. } \\
\text { b. Two measurements higher or equal to } 100 \mathrm{~mm} \mathrm{Hg} \text { diastolic or } 160 \mathrm{~mm} \mathrm{Hg} \text { systolic. } \\
\text { c. Three measurements higher or equal to } 90 \mathrm{~mm} \mathrm{Hg} \text { diastolic or } 140 \mathrm{~mm} \mathrm{Hg} \text { systolic. } \\
\text { 3. Treatment-a patient who was treated with three prescribed antihypertensive medications from } 1 \text { y prior } \\
\text { to the examination period until the present examination. }\end{array}$ \\
\hline Diabetes & $\begin{array}{l}\text { 1. Having a valid military disability code for diabetes. } \\
\text { 2. Prescribed medications for diabetes, other than the Glucophage category within the preceding year, } \\
\text { from } 1 \text { y before the examination period until the present examination. } \\
\text { 3. Prescribed medications for diabetes, from the Glucophage category, from } 1 \text { y before the examination } \\
\text { period until the present examination. } \\
\text { 4. Receiving prescription (code ICD } 250 \text { ) following the diagnosis of diabetes mellitus. } \\
\text { 5. Results of HbA1c above } 6.5 \% \text { at any stage before the examination period. } \\
6 \text {. Results of blood-glucose levels above } 200 \mathrm{mg} / \mathrm{dL} \text { on the year before the examination period. }\end{array}$ \\
\hline Hyperlipidemia & $\begin{array}{l}\text { 1. An LDL test was made in the last } 5 \mathrm{y} \text {, and in the last examination checkup, they received an LDL test result } \\
\text { of } 160 \text { and above. } \\
\text { 2. The lipid profile test was taken in the last } 5 \mathrm{y} \text {, and in the last examination the triglyceride results were } \\
\text { above } 200 \text {, and the non-HDL cholesterol result was above } 190 \text {. } \\
\text { 3. Valid military disability code for hypertension. }\end{array}$ \\
\hline
\end{tabular}

Abbreviations: ICD, International Classification of Diseases; LDL, low-density lipoprotein. 
Table 3 Multicollinearity tests: Pearson's correlation between socio-demographic parameters

\begin{tabular}{|c|c|c|c|c|c|c|c|c|}
\hline & & Sex & Education & SES & Age & Medical profile & QGS score & ICS score \\
\hline \multirow[t]{2}{*}{ Sex } & Pearson Correlation & \multirow[t]{2}{*}{1.00} & 0.10 & 0.01 & 0.16 & 0.05 & 0.06 & 0.02 \\
\hline & Sig. (two-tailed) & & $<0.001$ & $<0.001$ & $<0.001$ & $<0.001$ & $<0.001$ & $<0.001$ \\
\hline \multirow[t]{2}{*}{ Education } & Pearson correlation & 0.10 & \multirow[t]{2}{*}{1.00} & 0.12 & 0.68 & -0.05 & 0.20 & 0.24 \\
\hline & Sig. (two-tailed) & $<0.001$ & & $<0.001$ & $<0.001$ & $<0.001$ & $<0.001$ & $<0.001$ \\
\hline \multirow[t]{2}{*}{ SES } & Pearson correlation & 0.01 & 0.12 & \multirow[t]{2}{*}{1.00} & 0.08 & 0.00 & 0.07 & 0.08 \\
\hline & Sig. (two-tailed) & $<0.001$ & $<0.001$ & & $<0.001$ & 0.0540 & $<0.001$ & $<0.001$ \\
\hline \multirow[t]{2}{*}{ Age } & Pearson correlation & 0.16 & 0.68 & 0.08 & \multirow[t]{2}{*}{1.00} & -0.10 & 0.08 & 0.09 \\
\hline & Sig. (two-tailed) & $<0.001$ & $<0.001$ & $<0.001$ & & $<0.001$ & $<0.001$ & $<0.001$ \\
\hline \multirow[t]{2}{*}{ Medical profile } & Pearson correlation & 0.05 & -0.05 & 0.00 & -0.10 & \multirow[t]{2}{*}{1.00} & 0.06 & 0.02 \\
\hline & Sig. (two-tailed) & $<0.001$ & $<0.001$ & 0.0540 & $<0.001$ & & $<0.001$ & $<0.001$ \\
\hline \multirow[t]{2}{*}{ QGS score } & Pearson correlation & 0.06 & 0.20 & 0.07 & 0.08 & 0.06 & \multirow[t]{2}{*}{1.00} & 0.90 \\
\hline & Sig. (two-tailed) & $<0.001$ & $<0.001$ & $<0.001$ & $<0.001$ & $<0.001$ & & $<0.001$ \\
\hline \multirow[t]{2}{*}{ ICS score } & Pearson correlation & 0.02 & 0.24 & 0.08 & 0.09 & 0.02 & 0.90 & \multirow[t]{2}{*}{1.00} \\
\hline & Sig. (two-tailed) & $<0.001$ & $<0.001$ & $<0.001$ & $<0.001$ & $<0.001$ & $<0.001$ & \\
\hline
\end{tabular}

Abbreviations: ICS, intellectual capability score; QGS, quality group score; SES, socio-economic status.

2. Body Mass Index (BMI) and the diagnosis of obesity - BMI is defined as the weight (in kilograms) in light clothing divided by height (in meters, without shoes) squared, as reported previously. ${ }^{78}$ Obesity was defined according to the modification of the World Health Organization subgroups as BMI $\geq 30 \mathrm{~kg} / \mathrm{m}^{2}$, as reported elsewhere. ${ }^{68}$ The absolute BMI values were also analyzed as a continuous variable.

\section{Medical and Dental Attendance Patterns}

These variables evaluate health care utilization during the study period:

1. The total number of dental appointments: the number of dental appointments the subject attended.
2. Non-attendance to scheduled dental appointments: failure to attend a scheduled dental appointment is recorded in the DPR, the total of missed appointments was calculated.

3. The total number of appointments with a general physician: the number of medical appointments the subject attended.

\section{Multicollinearity Analysis}

Data were tabulated, and statistical analyses were performed using SPSS software version 22.0 (IBM, Chicago, Illinois, United States). In our series of papers that are due to follow, we will present the data of each dental, periodontal, and oraldependent variable.

Multicollinearity analysis using Pearson's correlation was performed to assess correlations between independent variables. The statistical significance was set on 0.01 (two-

Table 4 Pearson's correlation between categorical medical parameters

\begin{tabular}{|c|c|c|c|c|c|c|c|}
\hline & & Hypertension & Diabetes & Hyperlipidemia & $\begin{array}{l}\text { Sleep } \\
\text { apnea }\end{array}$ & $\begin{array}{l}\text { Impaired glucose } \\
\text { tolerance }\end{array}$ & $\begin{array}{l}\text { Heart } \\
\text { disease }\end{array}$ \\
\hline \multirow[t]{2}{*}{ Hypertension } & Pearson correlation & \multirow[t]{2}{*}{1.00} & 0.10 & 0.06 & 0.04 & 0.03 & 0.10 \\
\hline & Sig. (two-tailed) & & $<0.001$ & $<0.001$ & $<0.001$ & $<0.001$ & $<0.001$ \\
\hline \multirow[t]{2}{*}{ Diabetes } & Pearson correlation & 0.10 & \multirow[t]{2}{*}{1.00} & 0.02 & 0.04 & 0.08 & 0.07 \\
\hline & Sig. (two-tailed) & $<0.001$ & & $<0.001$ & $<0.001$ & $<0.001$ & $<0.001$ \\
\hline \multirow[t]{2}{*}{ Hyperlipidemia } & Pearson correlation & 0.06 & 0.02 & \multirow[t]{2}{*}{1.00} & 0.03 & 0.01 & 0.03 \\
\hline & Sig. (two-tailed) & $<0.001$ & $<0.001$ & & $<0.001$ & 0.0008 & $<0.001$ \\
\hline \multirow[t]{2}{*}{ Sleep apnea } & Pearson correlation & 0.04 & 0.04 & 0.03 & \multirow[t]{2}{*}{1.00} & 0.02 & 0.04 \\
\hline & Sig. (two-tailed) & $<0.001$ & $<0.001$ & $<0.001$ & & $<0.001$ & $<0.001$ \\
\hline \multirow[t]{2}{*}{ Impaired glucose tolerance } & Pearson correlation & 0.03 & 0.08 & 0.01 & 0.02 & \multirow[t]{2}{*}{1.00} & 0.03 \\
\hline & Sig. (two-tailed) & $<0.001$ & $<0.001$ & 0.0008 & $<0.001$ & & $<0.001$ \\
\hline \multirow[t]{2}{*}{ Heart disease } & Pearson correlation & 0.10 & 0.07 & 0.03 & 0.04 & 0.03 & \multirow[t]{2}{*}{1.00} \\
\hline & Sig. (two-tailed) & $<0.001$ & $<0.001$ & $<0.001$ & $<0.001$ & $<0.001$ & \\
\hline
\end{tabular}

Note: Correlation is significant at the 0.01 level (two-tailed). 
tailed). A correlation result $r \geq 0.8$ was considered as an exclusion criterion to include both variables in the multivariate model. Multicollinearity analysis results of the study parameters are presented in -Tables 3 and 4.

\section{Discussion}

This paper describes the methods and protocol of the DOME study for assessing socio-demographics, health-related habits, medical and dental attendance patterns, general and dental health status. Due to the amount of the data assessed and appropriate for presentation, we decided to publish the methods as a separate paper and then analyze the results and present them in other papers.

Measurements of dental caries level and missing teeth: The oldest and most commonly cited measurement in global literature for caries evaluation is the decay missing filled index (DMF), developed by Klein et al $^{79}$ and modified by the World Health Organization. ${ }^{80}$ This measurement is used in epidemiological studies where a representative sample of the population is clinically examined using an explorer, mirror, and gauze (without X-ray imaging), checking the number of teeth with caries (decay), the number of teeth missing due to caries (missing), and the number of restored teeth due to caries (filled). This measurement sums the number of affected teeth and can be used at the resolution of morbidity of single teeth or at the level of which tooth surfaces are affected by caries. However, the DMF index has its limitations, especially due to the lack of integration of Xray imaging which may lead to undiagnosed and untreated hidden occlusal, or interproximal, caries. ${ }^{81}$ Since the DOME study is records based, it includes the routine evaluation of dental caries performed in IDF dental clinics, based on both clinical and radiological examinations.

Additionally, in the DMF, the evaluation of missing teeth is based only on teeth missing due to caries, and not due to other reasons The possibility of a patient recall bias regarding the cause of dental extraction was considered in the IDF, and therefore the missing teeth count includes missing teeth for any reason.

Evaluation of periodontitis: The clinical entity of "established periodontitis" is described in the literature following assessment of probing depth (at six sites around each tooth) and clinical attachment loss (the difference between probing depth and recession). ${ }^{66}$ In this study, the diagnostic criteria to assess periodontitis were strict and included both clinical and radiographic evaluation. Without a radiograph, the diagnosis of periodontal disease may be inaccurate. ${ }^{66}$ Moreover, the errors inherent to the use of a periodontal probe including variation in probing force, visual errors in identifying the cement-enamel junction (CEJ), relative attachment level landmarks, fluctuations in gingival inflammation (pseudo-pockets), and misrecording of measurements are well known. ${ }^{65}$ Therefore, the current study included alveolar bone loss as a requirement for diagnosing periodontal disease, based on the assumption that a "true" loss of periodontal support has occurred since the damage can only be seen in radiographs after 3 months. ${ }^{66}$ In support, the new 2018 periodontitis classification supports our strict protocol which utilizes radiographic attachment loss and includes an assessment of age, smoking, and medical co-morbidities as risk factors for future progression of alveolar bone loss. ${ }^{82,83}$

Evaluation of socio-demographic parameters: Education, race, and socio-demographic parameters are associated with higher oral health literacy, and therefore, affect the likelihood of seeking professional dental advice. ${ }^{84}$ Identifying atrisk populations for oral diseases, based on socioeconomic characteristics, enhances the effectiveness of preventive campaigns by focusing interventions, adopting specific strategies, and obtaining active participation of target populations. ${ }^{85}$ Israel is known as an immigrant's state. Specifically, the FSU and Ethiopia were considered as separate ethnic groups in the military database, as these populations immigrated to Israel in the 1990s and have unique cultural characteristics.

Evaluation of oral health-related habits: In 2016, the Israeli Central Bureau of Statistics reported a high carbohydrate consumption level among Israeli soldiers. ${ }^{70}$ Moreover, according to the Health knowledge, attitudes, and practice survey conducted by the Israeli ministry of health in 2011, $22.8 \%$ of the Israeli population consume sweet beverages daily. ${ }^{86}$ Therefore, the evaluation of oral health-related habits and their associations with dental and systemic morbidities in the DOME study is essential.

Evaluation of systemic morbidity: Data regarding systemic morbidity in the DOME study was based on doctor diagnoses, complex variable definitions (for diabetes, hypertension, and hyperlipidemia), auxiliary tests including blood examinations, medical attendance patterns, and medications taken by the patient. The complex variable definition bases a diagnosis on the results of several methods, such as clinical evaluation, auxiliary tests, and medications used. Complex variable definitions reduce the false positive rate that may arise from basing a diagnosis on a single measurement.

The complex variable definition is also in line with the new 2018 classification of periodontitis. ${ }^{83}$ One of the criteria for the diagnosis of diabetes in the complex variable definition is HbA1c $>6.5 \%$, which is a grade modifier in the new 2018 classification of periodontitis. ${ }^{83} \mathrm{HbA} 1 \mathrm{c}<7 \%$ is classified as grade $\mathrm{B}$ and $\mathrm{HbA} 1 \mathrm{C}>7 \%$ is classified as grade $\mathrm{C}$ in the new classification. ${ }^{83}$

The diagnosis of obesity is of importance in light of the report by the Knesset Labor, Social Affairs, and Health Committee, in 2016. They reported that $70 \%$ of military personnel gain weight during their service and $22 \%$ suffer from being overweight. ${ }^{87}$ Considering the world epidemic of "Diabesity," it is important to assess the metabolic profile of a nationally representative sample of young to middle-aged individuals, and its association with dental, periodontal, and oral morbidities.

\section{Strengths and Limitations}

The main strengths of the present study are the large sample size (132,354 dental attendees and $>50,000$ general military personnel of nonattendees) and the strict protocol for 
utilizing socio-demographic, medical, and dental databases. Record driven data did not rely on the reports of patients, which eliminates recall bias. The IDF socio-demographic, medical and dental systems are homogenous, with standardized, uniform administrative and clinical work-ups and treatment protocols and computerized codes. Clinical examination and radiographic assessment were included in the data for dental parameters, whereas clinical and laboratory data were included for the medical parameters. The large proportion of immigrants in Israel means that our data covers multiple ethnicities, which may enhance the generalizability of the results.

Limitations of this study include the possibility of recall bias in some self-reported health-related behaviors. Undesirable habits (e.g., smoking, cariogenic diet, etc.), may be underreported. Due to the cross-sectional study design, we cannot assume causality, and therefore the DOME study can only address associations and correlations between the variables. Although multiple ethnicities were included, the results can only be generalized to Jewish, Druze, and Circassian young and middle-aged adults who are current Israeli residents, and further studies are needed to explore residents of other countries.

\section{Conclusion}

The goal of the current manuscript was to present the study methods including the standardized terminology, data collection, and handling of the DOME study. Standardized workup and definitions are essential to establish a centralized socio-demographics, dental, and medical data repository to study the extent of dental and systemic morbidities and their associations. In the next papers, we will present the data on each specific dependent variable analyzed.

\section{Conflict of Interest}

None declared.

\section{References}

1 Kassebaum NJ, Bernabé E, Dahiya M, Bhandari B, Murray CJ, Marcenes W. Global burden of severe periodontitis in 19902010: a systematic review and meta-regression. J Dent Res 2014;93(11):1045-1053

2 Marcenes W, Kassebaum NJ, Bernabé E, et al. Global burden of oral conditions in 1990-2010: a systematic analysis. J Dent Res 2013; 92(07):592-597

3 Kassebaum NJ, Bernabé E, Dahiya M, Bhandari B, Murray CJ, Marcenes W. Global burden of untreated caries: a systematic review and metaregression. J Dent Res 2015;94 (05):650-658

4 MOH Ministry of Health Israel. Oral and dental health-goals for year 2020, Hebrew. 2016. Available at: https://www.health.gov.il/ PublicationsFiles/2020_18052016.pdf. Accessed January 1, 2019

5 Levy DH, Livny A, Sgan-Cohen H, Yavnai N. The association between caries related treatment needs and socio-demographic variables among young Israeli adults: a record based cross sectional study. Isr J Health Policy Res 2018;7(01):24

6 Twig G, Tirosh A, Derazne E, et al. Cognitive function in adolescence and the risk for premature diabetes and cardiovascular mortality in adulthood. Cardiovasc Diabetol 2018;17(01):154
7 Heymann AD, Shilo Y, Tirosh A, Valinsky L, Vinker S. Differences between soldiers, with and without emotional distress, in number of primary care medical visits and type of presenting complaints. Isr Med Assoc J 2007;9(02):90-93

8 Williams DR. Race, socioeconomic status, and health. The added effects of racism and discrimination. Ann N Y Acad Sci 1999; 896:173-188

9 Lynch JW, Smith GD, Kaplan GA, House JS. Income inequality and mortality: importance to health of individual income, psychosocial environment, or material conditions. BMJ 2000;320 (7243):1200-1204

10 Kumar N, Bhardwaj A, Negi PC, Jhingta PK, Sharma D, Bhardwaj VK. Association of chronic periodontitis with metabolic syndrome: a cross-sectional study. J Indian Soc Periodontol 2016; 20(03):324-329

11 Abdalla-Aslan R, Findler M, Levin L, et al. Where periodontitis meets metabolic syndrome-the role of common health-related risk factors. J Oral Rehabil 2019;46(07):647-656

12 Musskopf ML, Daudt LD, Weidlich P, Gerchman F, Gross JL, Oppermann RV. Metabolic syndrome as a risk indicator for periodontal disease and tooth loss. Clin Oral Investig 2017;21 (02):675-683

13 Jaramillo A, Contreras A, Lafaurie GI, et al. Association of metabolic syndrome and chronic periodontitis in Colombians. Clin Oral Investig 2017;21(05):1537-1544

14 Llambés F, Arias-Herrera S, Caffesse R. Relationship between diabetes and periodontal infection. World J Diabetes 2015;6 (07):927-935

15 Kawabata Y, Ekuni D, Miyai H, et al. Relationship between prehypertension/hypertension and periodontal disease: a prospective cohort study. Am J Hypertens 2016;29(03):388-396

16 Leong XF, Ng CY, Badiah B, Das S. Association between hypertension and periodontitis: possible mechanisms. ScientificWorldJournal 2014;2014:768237

17 Zhou X, Zhang W, Liu X, Zhang W, Li Y. Interrelationship between diabetes and periodontitis: role of hyperlipidemia. Arch Oral Biol 2015;60(04):667-674

18 Amin Hel-S. Relationship between overall and abdominal obesity and periodontal disease among young adults. East Mediterr Health J 2010;16(04):429-433

19 Kjellström B, Rydén L, Klinge B, Norhammar A. Periodontal disease-important to consider in cardiovascular disease prevention. Expert Rev Cardiovasc Ther 2016;14(09):987-989

20 Lafon A, Pereira B, Dufour T, et al. Periodontal disease and stroke: a meta-analysis of cohort studies. Eur J Neurol 2014;21(09): 1155-1161

21 Taylor GW, Borgnakke WS. Periodontal disease: associations with diabetes, glycemic control and complications. Oral Dis 2008;14 (03):191-203

22 Mealey BL, Rethman MP. Periodontal disease and diabetes mellitus. Bidirectional relationship. Dent Today 2003;22(04): 107-113

23 Abe S, Ishihara K, Adachi M, Okuda K. Oral hygiene evaluation for effective oral care in preventing pneumonia in dentate elderly. Arch Gerontol Geriatr 2006;43(01):53-64

24 Asai Y, Ohyama Y, Gen K, Ogawa T. Bacterial fimbriae and their peptides activate human gingival epithelial cells through Toll-like receptor 2. Infect Immun 2001;69(12):7387-7395

25 Itoh K, Udagawa N, Kobayashi K, et al. Lipopolysaccharide promotes the survival of osteoclasts via Toll-like receptor 4 , but cytokine production of osteoclasts in response to lipopolysaccharide is different from that of macrophages. J Immunol 2003;170 (07):3688-3695

26 Genco RJ, Genco FD. Common risk factors in the management of periodontal and associated systemic diseases: the dental setting and interprofessional collaboration. J Evid Based Dent Pract 2014; 14(suppl):4-16 
27 Sheiham A, Watt RG. The common risk factor approach: a rational basis for promoting oral health. Community Dent Oral Epidemiol 2000;28(06):399-406

28 Ezzati M, Riboli E. Can noncommunicable diseases be prevented? Lessons from studies of populations and individuals. Science 2012;337(6101):1482-1487

29 Bauer UE, Briss PA, Goodman RA, Bowman BA. Prevention of chronic disease in the 21st century: elimination of the leading preventable causes of premature death and disability in the USA. Lancet 2014;384(9937):45-52

30 Kontis V, Mathers CD, Rehm J, et al. Contribution of six risk factors to achieving the $25 \times 25$ non-communicable disease mortality reduction target: a modelling study. Lancet 2014;384(9941):427-437

31 Linden GJ, Lyons A, Scannapieco FA. Periodontal systemic associations: review of the evidence. J Periodontol 2013;84(Suppl 4): S8-S19

32 Medina-Solís CE, Pontigo-Loyola AP, Pérez-Campos E, et al. National survey of oral/dental conditions related to tobacco and alcohol use in Mexican adults. Int J Environ Res Public Health 2014;11(03):3169-3184

33 IDF IDF. Personal data-the medical profile. Available at: https:// www.mitgaisim.idf.il/\%D7\%9B\%D7\%AA\%D7\%91\%D7\%95\%D7\%AA/ english/tzav-rishon/the-medical-profile/\#/. Accessed January 16 , 2019

34 IDF. Volunteering in the IDF for military exemption recipients. Available at: https://www.kolzchut.org.il/en/Volunteering_in_the_IDF_for_Military_Exemption_Recipients. Accessed July 6, 2020

35 Czerninski R, Zadik Y, Vered M, et al. Demographic and clinical factors associated with referrals and compliance to biopsy of oral and maxillofacial lesions. J Oral Pathol Med 2014;43(05):364-370

36 Engelchin-Nissan E, Catan G, Oz N, et al. Utilization of Health Services by IDF Soldiers and Civilian Population at an Israeli HMO. Health Econ Outcome Res Open Access 2017;103:2-6

37 Bar-Dayan Y, Saed H, Boaz M, et al. Using electronic health records to save money. J Am Med Inform Assoc 2013;20(e1):e17-e20

38 Peled A, Gordon B, Twig G, et al. Hypertension and childhood migration: a nationwide study of 2.7 million adolescents. J Hypertens 2019;37(04):702-709

39 ADA. ADA (American Dental Association) Guide to Dental Procedures Reported with Area of the Oral Cavity or Tooth Anatomy (or Both). Version 1; 2018. Available at: http://www.ada.org/en/ publications/cdt/ada-dental-claim-form. Accessed January 01, 2019

40 Issue Information. J Clin Periodontol 2018;45(S20):i-V

41 Caton JG, Armitage G, Berglundh T, et al. A new classification scheme for periodontal and peri-implant diseases and conditions -introduction and key changes from the 1999 classification. J Clin Periodontol 2018;45(Suppl 20):S1-S8

42 Chapple ILC, Mealey BL, Van Dyke TE, et al. Periodontal health and gingival diseases and conditions on an intact and a reduced periodontium: consensus report of workgroup 1 of the 2017 World Workshop on the Classification of Periodontal and PeriImplant Diseases and Conditions. J Clin Periodontol 2018;45 (Suppl 20):S68-S77

43 Papapanou PN, Sanz M, Buduneli N, et al. Periodontitis: consensus report of workgroup 2 of the 2017 World Workshop on the Classification of Periodontal and Peri-Implant Diseases and Conditions. J Clin Periodontol 2018;45(Suppl 20):S162-S170

44 Tonetti MS, Greenwell H, Kornman KS. Staging and grading of periodontitis: framework and proposal of a new classification and case definition. J Clin Periodontol 2018;45(Suppl 20):S149-S161

45 Albandar JM, Susin C, Hughes FJ. Manifestations of systemic diseases and conditions that affect the periodontal attachment apparatus: case definitions and diagnostic considerations. J Clin Periodontol 2018;45(Suppl 20):S171-S189

46 Araujo MG, Lindhe J. Peri-implant health. J Clin Periodontol 2018; 45(Suppl 20):S230-S236
47 Berglundh T, Armitage G, Araujo MG, et al. Peri-implant diseases and conditions: consensus report of workgroup 4 of the 2017 World Workshop on the Classification of Periodontal and PeriImplant Diseases and Conditions. J Clin Periodontol 2018;45 (Suppl 20):S286-S291

48 Billings M, Holtfreter B, Papapanou PN, Mitnik GL, Kocher T, Dye BA. Age-dependent distribution of periodontitis in two countries: findings from NHANES 2009 to 2014 and SHIP-TREND 2008 to 2012. J Clin Periodontol 2018;45(Suppl 20):S130-S148

49 Cortellini P, Bissada NF. Mucogingival conditions in the natural dentition: narrative review, case definitions, and diagnostic considerations. J Clin Periodontol 2018;45(Suppl 20):S190-S198

50 Ercoli C, Caton JG. Dental prostheses and tooth-related factors. J Clin Periodontol 2018;45(Suppl 20):S207-S218

51 Fan J, Caton JG. Occlusal trauma and excessive occlusal forces: narrative review, case definitions, and diagnostic considerations. J Clin Periodontol 2018;45(Suppl 20):S199-S206

52 Fine DH, Patil AG, Loos BG. Classification and diagnosis of aggressive periodontitis. J Clin Periodontol 2018;45(Suppl 20):S95-S111

53 Hämmerle CHF, Tarnow D. The etiology of hard- and soft-tissue deficiencies at dental implants: a narrative review. J Clin Periodontol 2018;45(Suppl 20):S267-S277

54 Heitz-Mayfield LJA, Salvi GE. Peri-implant mucositis. J Clin Periodontol 2018;45(Suppl 20):S237-S245

55 Herrera D, Retamal-Valdes B, Alonso B, Feres M. Acute periodontal lesions (periodontal abscesses and necrotizing periodontal diseases) and endo-periodontal lesions. J Clin Periodontol 2018;45 (Suppl 20):S78-S94

56 Holmstrup P, Plemons J, Meyle J. Non-plaque-induced gingival diseases. J Clin Periodontol 2018;45(Suppl 20):S28-S43

57 Jepsen S, Caton JG, Albandar JM, et al. Periodontal manifestations of systemic diseases and developmental and acquired conditions: consensus report of workgroup 3 of the 2017 World Workshop on the Classification of Periodontal and Peri-Implant Diseases and Conditions. J Clin Periodontol 2018;45(Suppl 20):S219-S229

58 Lang NP, Bartold PM. Periodontal health. J Clin Periodontol 2018; 45(Suppl 20):S9-S16

59 Murakami S, Mealey BL, Mariotti A, Chapple ILC. Dental plaqueinduced gingival conditions. J Clin Periodontol 2018;45(Suppl 20): S17-S27

60 Needleman I, Garcia R, Gkranias N, et al. Mean annual attachment, bone level, and tooth loss: a systematic review. J Clin Periodontol 2018;45(Suppl 20):S112-S129

61 Renvert S, Persson GR, Pirih FQ, Camargo PM. Peri-implant health, peri-implant mucositis, and peri-implantitis: case definitions and diagnostic considerations. J Clin Periodontol 2018;45(Suppl 20): S278-S285

62 Schwarz F, Derks J, Monje A, Wang H-L. Peri-implantitis. J Clin Periodontol 2018;45(Suppl 20):S246-S266

63 Trombelli L, Farina R, Silva CO, Tatakis DN. Plaque-induced gingivitis: case definition and diagnostic considerations. J Clin Periodontol 2018;45(Suppl 20):S44-S67

64 Periodontology AAo. Task force report on the update to the 1999 classification of periodontal diseases and conditions. J Periodontol 2015;86(07):835-838

65 Gupta N, Rath SK, Lohra P. Comparative evaluation of accuracy of periodontal probing depth and attachment levels using a Florida probe versus traditional probes. Med J Armed Forces India 2015; 71(04):352-358

66 Savage A, Eaton KA, Moles DR, Needleman I. A systematic review of definitions of periodontitis and methods that have been used to identify this disease. J Clin Periodontol 2009;36(06):458-467

67 Shelef L, Laur L, Fruchter E. Characteristics of the suicidal soldier in the Israeli Defense Force-a review of literature. Disaster Mil Med 2015;1:10

68 Twig G, Geva N, Levine H, et al. Body mass index and infectious disease mortality in midlife in a cohort of 2.3 million adolescents. Int J Obes 2018;42(04):801-807 
69 Hartal M, Yavnai N, Yaniv G, Gertz SD, Fleshler E, Kreiss Y. Old challenges and new perspectives on developing military physicians: the first 4 years of the New Israeli Model. Mil Med 2016;181 (02):129-135

70 Statistics ICBo Israeli Central Bureau of Statistics. Socio-Economic Index of Local Authorities. Available at: https://www.cbs.gov.il/ EN/pages/default.aspx\#. Accessed June 15, 2019

71 Gross R, Brammli-Greenberg S, Gordon B, Rabinowitz J, Afek A. Population-based trends in male adolescent obesity in Israel 1967-2003. J Adolesc Health 2009;44(02):195-198

72 Twig G, Livneh A, Vivante A, et al. Mortality risk factors associated with familial Mediterranean fever among a cohort of 1.25 million adolescents. Ann Rheum Dis 2014;73(04):704-709

73 Furer A, Afek A, Beer Z, et al. Height at late adolescence and incident diabetes among young men. PLoS One 2015;10(08): e0136464

74 Twig G, Yaniv G, Levine H, et al. Body-mass index in 2.3 million adolescents and cardiovascular death in adulthood. N Engl J Med 2016;374(25):2430-2440

75 Peled A, Gordon B, Twig G, et al. Immigration to Israel during childhood is associated with diabetes at adolescence: a study of 2.7 million adolescents. Diabetologia 2017;60(11):2226-2230

76 Mandel D, Amital H, Zimlichman E, et al. Quality assessment program in primary care clinics: a tool for quality improvement. Int J Qual Health Care 2004;16(02):175-180

77 Bodner E, Ben-Artzi E, Kaplan Z. Soldiers who kill themselves: the contribution of dispositional and situational factors. Arch Suicide Res 2006;10(01):29-43

78 Leiba A, Twig G, Vivante A, et al. Prehypertension among 2.19 million adolescents and future risk for end-stage renal disease. J Hypertens 2017;35(06):1290-1296
79 Klein H, Palmer C, Knutson J. Studies on dental caries: I. dental status and dental needs of elementary school children. Public Health Rep 1938;53(19):751-765

80 WHO. World Health Organization: Oral health surveys: basic methods. 5th ed. 2013. Available at: https://apps.who.int/iris/ handle/10665/97035. Accessed August 25, 2020

81 Zadik Y, Bechor R. Hidden occlusal caries: challenge for the dentist. N Y State Dent J 2008;74(04):46-50

82 Papapanou PN, Sanz M, Buduneli N, et al. Periodontitis: consensus report of workgroup 2 of the 2017 world workshop on the classification of periodontal and peri-implant diseases and conditions. J Periodontol 2018;89(Suppl 1):S173-S182

83 Tonetti MS, Greenwell H, Kornman KS. Staging and grading of periodontitis: framework and proposal of a new classification and case definition. J Periodontol 2018;89(Suppl 1):S159-S172

84 Holtzman JS, Atchison KA, Macek MD, Markovic D. Oral health literacy and measures of periodontal disease. J Periodontol 2017; 88(01):78-88

85 Boillot A, El Halabi B, Batty GD, Rangé H, Czernichow S, Bouchard P. Education as a predictor of chronic periodontitis: a systematic review with meta-analysis population-based studies. PLoS One 2011;6(07):e21508

86 Aflalo E, Dichtiar R, Zusman SP, Bilenko N, Keinan-Boker L. The association between health attitudes and behaviors and oral-health-related practices. Quintessence Int 2018;49(02): 153-162

87 Siegel-Itzkovich J. Diabetes expert: IDF soldiers gain weight during their service. 2016. Available at: https://www.jpost.com/ Business-and-Innovation/Health-and-Science/Diabetes-expertIDF-soldiers-gain-weight-during-their-service-441321. Accessed August 8, 2020 